\title{
Pengaruh Budaya Organisasi, Dan Displin Kerja, Terhadap Kinerja Karyawan Pada Klinik Tumbuh Kembang Yamet Pamulang
}

\author{
Fahmi Susanti \\ Dosen Fakultas Ekonomi Universitas Pamulang \\ Email : dosen02024@unpam.ac.id
}

\begin{abstract}
ABSTRAK
Tujuan penelitian untuk mengetahui pengaruh budaya organisasi dan disiplin kerja terhadap kinerja karyawan pada Klinik Tumbuh kembang Yamet. , baik parsial maupun simultan. Metode penelitian adalah deskriptif kuantitatif. Metode analisis yaitu analisis regresi linier berganda dengan populasi seluruh karyawan ( 50 karyawan) adapun sampel sejumlah 50 karyawan, teknik sampling penelitian ini teknik jenuh atau sensus.

Hasil uji hipostesis budaya organisasi serta disiplin kerja secara parsial nilai $t_{\text {hitung }}$ masing-masing sebesar $19,267,15,822$ semua nilai $t_{\text {hitung }}>t_{\text {tabel }}$. Untuk pengaruh simultan diperoleh $\mathrm{F}_{\text {hitung }}>\mathrm{F}_{\text {tabel }}$ yaitu $145,428>2,46$. Taraf signifikansi $\alpha=0,05$. Disimpulkan bahwa budaya organisasi dan disiplin kerja secara parsial maupun simultan berpengaruh signifikan terhadap kinerja karyawan klinik tumbuh kembang Yamet.

Dengan persamaan regresi linier $\hat{Y}=0,249+0,638 X_{1}+0,406 X_{2}$ budaya organisasi dan disiplin kerja mempunyai kemampuan untuk memberikan pengaruh kinerja karyawan klinik tumbuh kembang Yamet. Nilai koefisien determinasi 0,928 atau $92,8 \%$ memberikan penjelasan bahwa budaya organisasi, disiplin kerja mempunyai kemampuan mempengaruhi kinerja karyawan klinik tumbuh kembang Yamet sebesar 92,8 \% sisanya sebesar 7,2\% pengaruh variabel bebas lainnya yang tidak diteliti.
\end{abstract}

Kata Kunci: Budaya Organisasi, Disiplin kerja, Kinerja Karyawan. 


\section{PENDAHULUAN}

\section{A. Latar Belakang}

Kompetisi yang ketat sebagai efek dari perkembangan globalisasi teknologi dan menjadikan Sumber Daya Manusia (SDM) adalah faktor utama di kegiatan organisasi, manusia menjadi posisi strategis dalam semua kegiatan institusi. Untuk tetap dapat eksis masalah sumber daya manusia masih menjadi masalah utama bagi organisasi/instistusi. Menurut Malthis dan Jackson dalam Sumarsono (2013:81) mengemukakan bahwa dengan melalui pemanfaatan sumber daya manusia yang efisien dan efektif, perusahaan berharap agar dapat terus bertahan di arena persaingan yang kian sengit untuk memperoleh eksistensi. Faktor budaya pada organisasi, faktor disiplin kerja organisasi sebagai potensi yang akan memiliki pengaruh besar dalam hasil kinerja pegawai. Menurut Boejong Lukito (1995) Budaya organisasi yang kuat akan berpengaruh positif pada kinerja bisnis. Malthis \& Jackson mengemukakan bahwa disiplin kerja berkaitan erat dengan perilaku kerja dan berpengaruh terhadap kinerja. Makin tingginya disiplin kerja seseorang akan makin tinggi pula hasil kerja karyawan pada tempat bekerjanya.

\section{B. Perumusan Masalah}

1. Seberapa besar kah pengaruh antara budaya organisasi terhadap kinerja karyawan Klinik Tumbuh Kembang Yamet?

2. Seberapa besarkah pengaruh antara disiplin kerja terhadap kinerja karyawan klinik tumbuh kembang Yamet?

3. Seberapa besarkah pengaruh antara variabel budaya organisasi, serta di siplin secara simultan terhadap kinerja karyawan tumbuh kembang Yamet?

\section{Pembatasan Masalah}

Dalam penelitian ini penulis memberikan pembatasan hal diteliti, yaitu mengenai budaya organisasi, disiplin kerja dan kinerja karyawan di Klinik tumbuh kembang Yamet.

\section{Tujuan Penelitian}

Adapun tujuan penelitian adalah untuk memberikan jawaban atas perumusan masalah :

1. Untuk mengetahui pengaruh antara budaya organisasi terhadap kinerja karyawan Klinik tumbuh kembang Yamet

2. Untuk mengetahui pengaruh antara disiplin kerja terhadap kinerja 
karyawan Klinik tumbuh kembang Yamet .

3. Untuk mengetahui pengaruh antara budaya organisasi dan disiplin kerja secara simultan terhadap kinerja karyawan Klinik tumbuh kembang Yamet

\section{TINJAUAN PUSTAKA}

\section{A. Manajemen}

Menurut W.Griffin (2007:43)

Manajemen adalah sebuah proses perencanaan, pengorganisasian, pengkoordinasian dan pengontrolan sumber daya untuk mencapai sasaran (goals) secara efektif dan efisien. . Menurut Malayu SP. Hasibuan (2000:2) Manajemen adalah ilmu (sekumpulan pengetahuan yang sistematis, telah dikumpulkan dan diterima secara umum dengan suatu objek atau objek tertentu) dan seni mengatur proses pemanfaatan. Sumber Daya Manusia dan sumber sumber lainnya secara efektif dan efisien untuk mencapai suatu tujuan.

\section{B. Manajemen SDM (Sumber Daya Manusia)}

Menurut Malayu SP. Hasibuan (2006:10), Manajemen Sumber daya manusia (MSDM) adalah ilmu dan seni mengatur hubungan dan peranan tenaga kerja agar efektif dan efisien membantu terwujudnya tujuan perusahaaan, karyawan, dan masyarakat. Sumber Daya Manusia dalam suatu perusahaan berperan penting sebagai penggerak aktivitasnya perusahan tersebut. oleh karena itu dengan alasan tersebut, pengolahan sumber daya manusia merupakan masalah yang harus dihadapi oleh perusahaan atau organisasi agar dapat beraktivitas dengan baik dan lancar.

\section{Budaya Organisasi}

Hofstede dalam Fuad Mas'ud (2004) mengatakan bahwa budaya organisasi adalah nilai- nilai yang dipelihara dan dipertahankan. Indikator oleh Hofstede. tersebut jarak dari manajemen karyawan, profesionalisme karyawan, sikap terbuka dan integrasi karyawan.

\section{Disiplin Kerja}

Veithzal Rivai (2011:825) menjelaskan dsiplin kerja adalah suatu alat yang dipergunakan para manajer untuk berkomunikasi dengan karyawan agar mereka bersedia untuk mnegubah suatu perilaku serta sebagai suatu upaya untuk meningkatkan kesadaran dan kesediaan seorang dalam memenuhi segala peraturan perusahaan.

\section{E. Kinerja karyawan}

Menurut Mangkunegara (2011:67).Kinerja adalah hasil kerja secara kualitas dan kuantitas yang dicapai oleh seorang pegawai dalam melaksanakan tugasnya sesuai dengan tanggung jawab yang diberikan kepadanya. Kinerja didefinisikan oleh Robbins sebagai hasil pencapaian kerja individu yang menggambarkan usaha yang dilakukan untuk mencapai sasaran. 


\section{Kerangka Pemikiran}

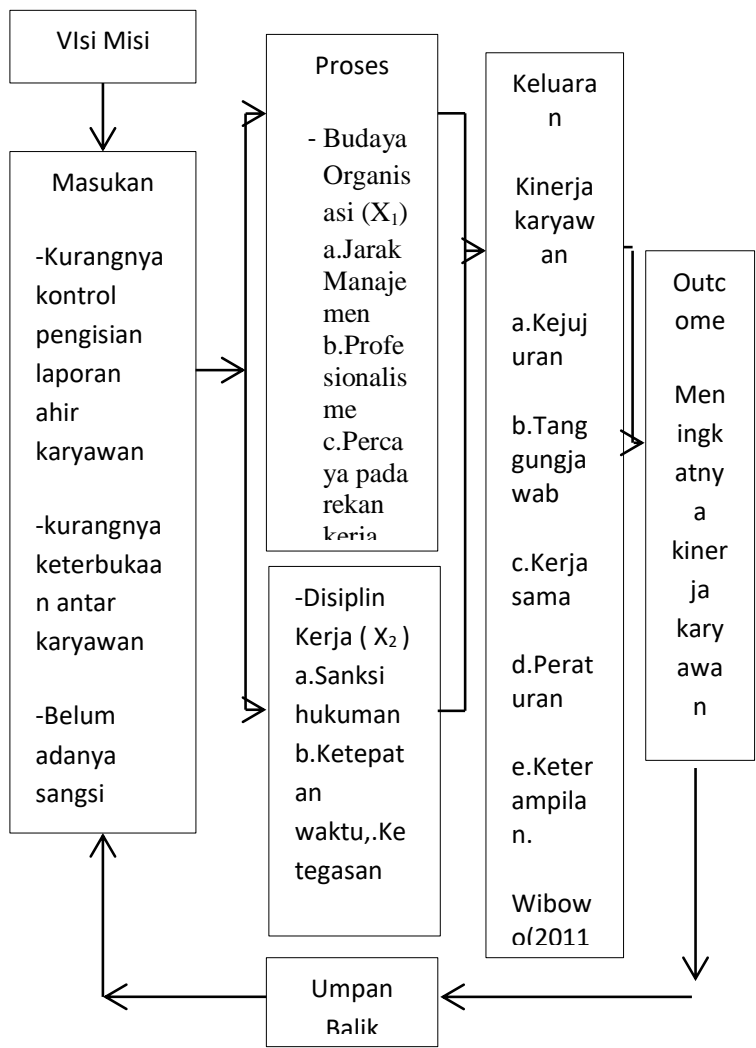

Gambar 2.1 : Kerangka Pemikiran Penelitian

\section{F. Hipotesis}

Penelitian.

Adapun hipotesis yang penulis ajukan adalah sebagai berikut:

1. Diduga variabel budaya organisasi berpengaruh positif dan signifikan terhadap kinerja karyawan.

2. Diduga variabel disiplin kerja berpengaruh positif dan signifikan terhadap kinerja karyawan.

3. Diduga budaya organisasi, dan disiplin kerja berpengaruh positif dan signifikan secara simultan terhadap kinerja karyawan.

\section{METODE PENELITIAN}

A. Tempat dan Waktu Penelitian

Objek di Klinik Tumbuh Kembang Yamet Pamulang, dilaksanakan pada bulan Juli 2017 sampai dengan Desember 2017.

\section{B. Metode Penelitian}

Yaitu penelitian deskriptif kuantitatif yaitu pengambilan sampelnya secara langsung dari populasi. Dengan maksud untuk analisis pengaruh Budaya Organisasi $\left(\mathrm{X}_{1}\right)$, dan Disiplin kerja $\left(\mathrm{X}_{2}\right)$, terhadap Kinerja karyawan (Y). Menurut Sugiyono (2007:13) Penelitian Kuantitatif adalah metode penelitian yang berlandaskan pada filsafat positisme, digunakan untuk meneliti pada populasi atau sampel tertentu. Jenis Penelitian disini adalah eksplanatori (penjelasan) penelitian eksplanatori melakukan studi terhadap pengaruh antara dua atau lebih variabel, kemudian berusaha menjelaskan fenomena yang terjadi.

\section{Populasi dan Sampel}

\section{Populasi}

Populasi adalah semua obyek, semua gejala dan semua kejadian atau peristiwa yang akan dipilih harus sesuai dengan masalah 
yang akan diteliti, Hadi

(2012:75). Populasi

dalam penelitian ini

adalah karyawan

Klinik Tumbuh

Kembang Yamet

Pamulang Tahun 2017

sejumlah 50 orang.

2. Sampel

Sampel adalah

sebagian dari populasi

yang karakteristiknya

dianggap dapat

mengganti keseluruhan

populasi tersebut

Djarwanto dan

Subagyo(2012:36).

Teknik sampling yang disini adalah sampel jenuh atau sensus

Adapun tingkat kesalahan yang akan digunakan dalam penarikan sampel ini adalah 5\%. Dengan jumlah populasi $(\mathrm{N})$ sejumlah 50 orang, maka besarnya sampel disini 50 orang.

D. Teknik Penentuan Data

1. Data Primer

2. Data Sekunder

\section{E. Metode Analisis Data}

1. Uji Validitas

Uji validitas

digunakan untuk

melakukan

pengukuran sah atau

tidak sah suatu

kuesioner.

peneliti memakai

korelasi Produk

Momen yaitu dengan cara melakukan

pengkorelasian skor item dengan skor total sehingga diperoleh nilai $r$ hitung yang selanjutnya

dibandingkan dengan $r$ tabel

2. Uji Reliabilitas

Reliabilitas berkenaan dengan derajat konsistensi dan stabilitas data atau temuan. Sugiyono (2011:268).

\section{3 . Uji Asumsi Klasik}

a. Uji Normalitas memiliki tujuan untuk melakukan pengujian dalam model regresi tersebut, variabel independen dan variabel dependen apakah memiliki

distribusi data normal atau hampir dekat dengan data yang normalnya.

b. Uji

\section{Multikolinierita}

S

multikolinieritas

dipakai peneliti untuk melakukan pengujian

mengenai ada korelasi di antara dua variable yang ada : Variabel Budaya organisasi dan variable disiplin kerja terhadap 
kinerja karyawan

Variabel Klinik

Tumbuh

Kembang Yamet,

VIF (Variance

Inflation factor)

yang didapat

kurang dari 10

dan memiliki

nilai toleransinya

lebih 0.1 atau

$10 \%$.

c. Uji

Heteroskedastisi

tas

Dalam Sugiyono

(2013 : 124)

Heterokedastisita

$\mathrm{s}$ menunjukkan

bahwa varians

variabel tidak

sama untuk

semua

pengamatan/obse

rvasi.

\section{Rancangan Pengujian Hipotesis}

a. Uji t ( Parsial)

Untuk dilakukan uji

variabel yang

berpengaruh antara

budaya organisasi

dan disiplin kerja

terhadap kinerja

karyawan Kilinik

Tumbuh Kembang

Yamet, secara

individual

b Koefisien

Determinasi

Uji Koefisien

Determinasi dipakai untuk mencari tau \% nilai kinerja pegawai Klinik

Tumbuh kembang

Yamet sebagai

varibel terikat yang

dapat dijelaskan

oleh garis regresi.

c. Analisis Regresi

1) Analisis Regresi

Sederhana

Menurut

Sugiyono ( 2012

: 153) bahwa

Analisis Regresi

digunakan untuk

melakukan

prediksi

bagaimana

perubahan nilai

variabel

independen

dinaik/ turunkan.

2) Analisis

Regresi

Berganda

Menurut Gozali (2006 : 82)

Analisis Regresi

Linier Berganda

adalah

persamaan

regresi

digunakan untuk mengetahui ada tidak pengaruh Variabel terikat dengan variabel variabel bebas yang berjumlah lebih dari satu (1).

d. Uji F ( Simultan)

Untuk melakukan

uji variabel yang berpengaruh antara, budaya

organisasidan 


\begin{tabular}{|c|c|c|c|c|}
\hline No & Pernyataan & $\begin{array}{l}\mathbf{r} \\
\text { Hitung }\end{array}$ & $\begin{array}{l}\mathbf{r} \\
\text { Tabel }\end{array}$ & $\begin{array}{l}\text { Ket. } \\
\text { Butir }\end{array}$ \\
\hline 1 & $\begin{array}{l}\text { Butir } \\
\text { pernyataan } 1\end{array}$ & 0.707 & 0,24 & Valid \\
\hline 2 & $\begin{array}{l}\text { Butir } \\
\text { pernyataan } 2\end{array}$ & 0797 & 0,24 & Valid \\
\hline 3 & $\begin{array}{l}\text { Butir } \\
\text { pernyataan } 3\end{array}$ & 0.486 & 0,24 & Valid \\
\hline & & \multicolumn{3}{|c|}{$\begin{array}{lr}\text { disiplin } & \text { kerja } \\
\text { terhadap } & \text { kinerja } \\
\text { karyawan } & \text { klinik } \\
\text { tumbuh } & \text { kembang } \\
\text { Yamet } & \text { secara }\end{array}$} \\
\hline
\end{tabular}

HASIL DAN PEMBAHASAN

A. Hasil Uji Instrumen Penelitian

1. Hasil Uji Validitas Sugiyono (2009:172) dalam melakukan uji validitas yang menentukan validitas pada setiap pernyataan yang ada dalam kuesioner adalah dengan melihat besarnya $\mathrm{r}_{\text {tabel }}$ product moment, $d f=(\dot{\alpha}, \mathrm{n}-2)$. sumber data ini yang sejumlah 50 orang karyawan, didapatkan $r_{\text {tabel }}$ $=0,24$ dengan tingkat signifikansi $<0,05$. Jika $r_{\text {hitung }}>r_{\text {tabel }}$ maka variabel tersebut valid dan sebaliknya jika $r_{\text {hitung }}<$ $\mathrm{r}_{\text {tabel }}$ maka variabel tersebut tidaklah valid.

Dari hasil output table 4.1 (uji validitas variable budaya organisasi, tabel 4.2 (uji validitas variable disiplin) dan tabel 4.3 (uji validitas variable kinerja karyawan) yang telah dilakukan terhadap item item variabel, maka dapat diketahui bahwa nilai $\mathrm{r}$ hitung memiliki nilai lebih dari nilainya $\mathrm{r}$ tabel yaitu $>0,24$ sehingga dinyatakan valid.

Tabel 4.1 Uji Validitas Variabel Budaya Organisasi $\left(\mathbf{X}_{1}\right)$

Sumber: Hasil Olah Data SPSS

Tabel 4.2 Uji Validitas Variabel Disiplin Kerja $\left(\mathrm{X}_{2}\right)$.

\begin{tabular}{|l|l|l|l|l|}
\hline No & Pernyataan & $\begin{array}{l}\mathrm{r} \\
\text { hitung }\end{array}$ & $\begin{array}{l}\mathrm{r} \\
\text { tabel }\end{array}$ & $\begin{array}{l}\text { Ket } \\
\text { butir }\end{array}$ \\
\hline 1 & $\begin{array}{l}\text { Butir } \\
\text { pernyataan } \\
1\end{array}$ & 0,884 & 0,24 & valid \\
\hline 2 & $\begin{array}{l}\text { Butir } \\
\text { pernyataan } \\
2\end{array}$ & 0,865 & 0,24 & valid \\
\hline 3 & $\begin{array}{l}\text { Butir } \\
\text { pernyataan } \\
3\end{array}$ & 0,947 & 0,24 & valid \\
\hline \multicolumn{4}{|c|}{ Sumber: Hasil Olah Data SPSS } \\
\hline
\end{tabular}

Tabl 4.3 Uji Validitas Variabel Kinerja karyawan

\begin{tabular}{|l|l|l|l|l|}
\hline No & Pernyataan & $\begin{array}{l}\mathbf{r} \\
\text { Hitung }\end{array}$ & $\begin{array}{l}\mathbf{r} \\
\text { Tabel }\end{array}$ & $\begin{array}{l}\text { Ket. } \\
\text { Butir }\end{array}$ \\
\hline 1 & $\begin{array}{l}\text { Butir } \\
\text { pernyataan 1 }\end{array}$ & 0.811 & 0,24 & Valid \\
\hline 2 & $\begin{array}{l}\text { Butir } \\
\text { pernyataan 2 }\end{array}$ & 0.842 & 0,24 & Valid \\
\hline 3 & $\begin{array}{l}\text { Butir } \\
\text { pernyataan 3 }\end{array}$ & 0.675 & 0,24 & Valid \\
\hline \multicolumn{4}{|c|}{ Sumber: Hasil Olah Data SPSS } \\
\hline
\end{tabular}

2. Hasil Uji Reliabilitas.

Seluruh variabel yang digunakan menurut kriteria Nunaly (1967) dalam Gozali2006: 182 disebut reliabel, jika mempunyai nilai Conbrach lebih dari 0,6. Berdasarkan uji reliabilitas untuk variabel Budaya Organisasi $\left(\mathrm{X}_{1}\right)$, diperoleh $\mathrm{r}_{\text {Alpha }}$ sebesar 0,787 variabel disiplin kerja $\left(\mathrm{X}_{2}\right)$, diperoleh $\mathrm{r}_{\text {Alpha }}$ sebesar 0,932 variabel Kinerja (Y), diperoleh 
$\mathrm{r}_{\text {Alpha }}$ sebesar 0,863 dari 12 (dua belas ) butir pernyataan yang diajukan dengan jumlah responden 50 diperoleh hasil nilai Conbrach besarnya lebih 0,6 Jadi diambil kesimpulan, dari 12 (duabelas) butir pernyataan dalam setiap variabel yang telah diajukan semuanya reliabel dengan interpretasi kuat sehingga variabel tersebut layak digunakan untuk alat pengukur. Hasil uji reabilitas adalah seperti dibawah ini :

Tabel 4.4 uji Reabilitas

\begin{tabular}{|l|l|l|l|l|}
\hline $\begin{array}{l}\mathrm{N} \\
\text { o }\end{array}$ & $\begin{array}{l}\text { Perny } \\
\text { ataan }\end{array}$ & $\begin{array}{l}\text { rhi } \\
\text { tun } \\
\text { g }\end{array}$ & $\begin{array}{l}\mathbf{r} \\
\text { ta } \\
\text { b } \\
\text { el }\end{array}$ & $\begin{array}{l}\text { Ket } \\
\text { ir } \\
\text { But }\end{array}$ \\
\hline 1 & $\begin{array}{l}\text { Buda } \\
\text { ya } \\
\text { Organ } \\
\text { isasi } \\
\text { (X) }\end{array}$ & $\begin{array}{l}0 . \\
78\end{array}$ & 0 & $\begin{array}{l}\text { Rel } \\
\text { iab } \\
\text { el }\end{array}$ \\
\hline 2 & $\begin{array}{l}\text { Disipl } \\
\text { in } \\
\text { Kerja( } \\
\text { X2) }\end{array}$ & $\begin{array}{l}0 . \\
93\end{array}$ & 0 & $\begin{array}{l}\text { Rel } \\
\text { iab } \\
\text { el }\end{array}$ \\
\hline 3 & $\begin{array}{l}\text { Kinerj } \\
\text { a } \\
\text { Karya } \\
\text { wan( } \\
\text { Y) }\end{array}$ & $\begin{array}{l}0 . \\
86\end{array}$ & 0 & $\begin{array}{l}\text { Rel } \\
\text { iab } \\
\text { el }\end{array}$ \\
\hline
\end{tabular}

Sumber : Hasil olah data PSS
3. Hasil Uji Asumsi Klasik. a. Uji Normalitas Data

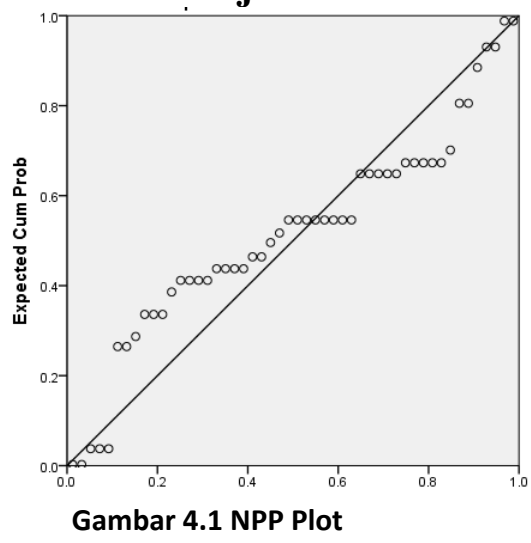

Dapat dilihat dari gambar 4.1 penyebaran plot disekitar garis dan mengikuti garis diagonal, bisa diartikan bahwa nilai residual yang dihasilkan dari regresi tersebut dikatakan normal. Setelah itu dilakukan dengan pengujian Uji One Sample Kolomogorov Smirnov digunakan untuk mengetahui distribusi data, apakah mengikuti distribusi normal. Dalam hal ini untuk mengetahui apakah distribusi residual terdistribusi normal atau tidak.

Residual berdistribusi normal jika nilai signifikansi lebih dari

0,05 .

\section{b. Hasil Uji}

Multikolinieritas

Tabel 4.5

\begin{tabular}{|ll|l|l|}
\hline \multirow{2}{*}{ Model } & \multicolumn{2}{|l|}{ Collinearity Statistics } \\
\cline { 3 - 4 } & & Tolerance & VIF \\
\hline 1 & X1 & .257 & 3.884 \\
& X2 & .257 & 3.884 \\
\hline
\end{tabular}




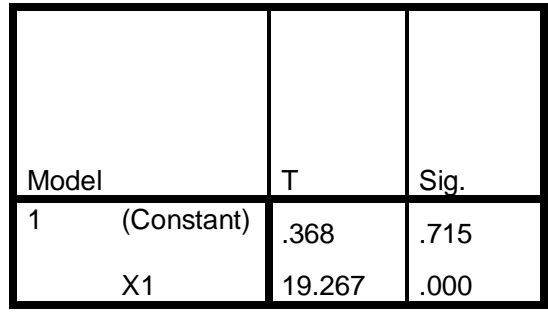

Hasil Multikolinieritas

Dari hasil output data didapatkan bahwa nilai VIF $<10$ dan nilai tolerance $>0,10$ maka tidak terjadi gejala Multikolinieritas.

c. Hasil Uji Heteroskedastisitas

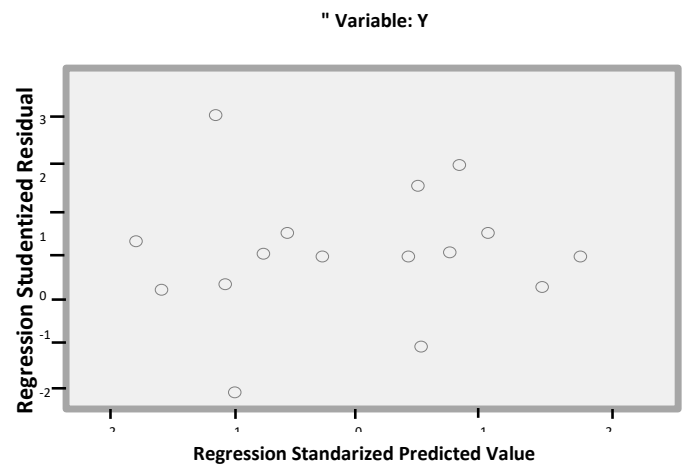

Gambar 4.2 Uji Heterokedastisitas

Dari output di atas dapat kita ketahui penyebaran terlatak pada bawah dan atas sumbu Y di angka 0 . kesimpulanya masalah heteroskedastisitas tidak ada.

B. Analisis Verifikatif

1.Hasil Pengaruh secara Partial Tabel 4.6 Hasil Pengujian Hipotesis Budaya Organisasi $\left(\mathrm{X}_{1}\right)$ terhadap Kinerja karyawan $(\mathrm{Y})$

Berdasarkan output tabel 4.6 diperoleh hasil sebagai berikut: Hasil uji parsial menunjukkan ada terdapat pengaruh positif variabel budaya organisasi terhadap variabel kinerja dilihat dari nilai $\mathrm{t}$ hitung untuk variabel budaya organisasi (19.267) > nilai $\mathrm{t}$ tabel $(2,01)$ dan terdapat pengaruh yang signifikan variabel budaya organisasi terhadap variabel kinerja karyawan , didapat nilai signifikansi t untuk variabel budaya organisasi dengan signifikan $(0,000)$ lebih kecil dari batas nilai signifikansi sebesar $(0,05)$, maka $\mathrm{H}_{\mathrm{o}}$ akan ditolak dan $\mathrm{H}_{\mathrm{a}}$ diterima untuk variabel budaya organisasi. Dengan demikian, secara parsial variabel budaya organisasi berpengaruh positif dan signifikan dengan pada klinik tumbuh kembang Yamet.

\section{Hasil Koefisien Determinasi ( $R$ Square) / $\mathbf{X}_{1}$ terhadap $Y$.}

Tabel 4.7 Hasil Koefisien Determinasi (RSquare) / $\mathbf{X}_{1}$ terhadap Y

\begin{tabular}{|l|l|l|l|l|}
\hline $\begin{array}{l}\text { Mo- } \\
\text { del }\end{array}$ & $R$ & $\begin{array}{l}R \\
\text { Square }\end{array}$ & $\begin{array}{l}\text { Adjusted R } \\
\text { Square }\end{array}$ & Std. Error of \\
\hline 1 & $.941^{\mathrm{a}}$ & .886 & .883 & .28013 \\
\hline
\end{tabular}

Berdasarkan output $4.7 \mathrm{R}$ square 0,886 dan diubah menjadi persen yaitu $88,6 \%$. Berarti budaya organisasi pengaruhnya pada kinerja karyawan di klinik tumbuh kem bang Yamet adalah sebesar $88,6 \%$ dan $11,4 \%$ sebagai pengaruh variabel bebas lain yang tidak dilakuksn penelitian saat ini.

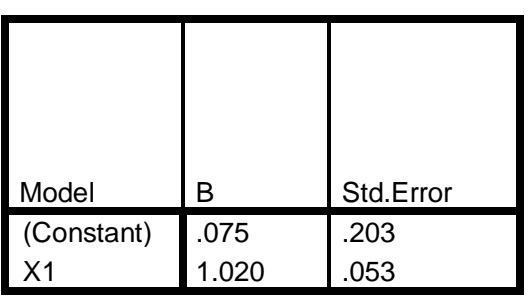

Hasil Analisis Regresi / $X_{1}$ terhadap Y.

Tabel 4.8 Hasil Analisis Regresi / $\mathrm{X}_{1}$ terhadap Y. 
Berdasarkan output pada tabel ini 4.8, dalam penelitian : $\hat{Y}=0,75+1.020$ $\mathrm{X}_{1}$ Penjelasannya adalah : Konstanta sebesar 0,75 menyatakan bahwa tanpa variabel budaya organisasi , kinerja mempunyai nilai yaitu sebesar 0,75. Nilai coefficents sebesar 1.020 mempunyai arti jika budaya organisasi naik satu satuan kinerjapun naik 1020. Pada persamaan tersebut dapat dilihat budaya organisasi memiliki kemampuan untuk mempengaruhi kinerja karyawan klinik tumbuh kembang Yamet. Hal ini menunjukkan bahwa kinerja karyawan klinik tumbuh kembang Yamet dapat dipengaruhi oleh budaya organisasi.

\section{Hasil Pengujian Hipotesis Disiplin kerja $\left(\mathbf{X}_{2}\right)$ terhadap Kinerja karyawan (Y)}

Tabel 4.9 Hasil Pengujian Hipotesis Disiplin Kerja (X2) terhadap Kinerja karyawan (Y)

\begin{tabular}{|c|c|c|}
\hline Model & $\mathrm{T}$ & Sig \\
\hline $\begin{array}{ll}1 & \text { (Constant) } \\
& \text { X2 }\end{array}$ & $\begin{array}{l}.653 \\
15.822\end{array}$ & $\begin{array}{l}.517 \\
.000\end{array}$ \\
\hline
\end{tabular}

Pada output tabel ini 4.9, hasil : Hasil uji parsial menunjukkan bahwa ada pengaruh positif variabel disiplin kerja terhadap variabel kinerja dilihat dari nilai $\mathrm{t}$ hitung untuk variabel disiplin kerja $(15,822)$ adalah lebih dari nilai $\mathrm{t}$ tabel $(2,01)$ disimpulkan terdapat pengaruh yang signifikan variabel disiplin kerja terhadap variabel kinerja ,nilai signifikansi t untuk variabel disiplin kerja dengan signifikan $(0,000)$ lebih kecil dari batas nilai signifikansi sebesar $(0,05)$, maka H0 akan ditolak Ha diterima untuk motivasi variable. Dengan demikian, secara parsial variabel disiplin kerja berpengaruh positif dan signifikan terhadap kinerja karyawan pada klinik tumbuh kembang Yamet.

\section{Hasil Koefisien Determinasi(R-}

\section{Square) / $\mathrm{X}_{2}$ terhadap $\mathrm{Y}$.}

Tabel 4.10 Hasil Koefisien Determinasi X2 terhadap

\begin{tabular}{|l|l|l|l|l|}
\hline $\begin{array}{l}\text { Mode } \\
1\end{array}$ & $\mathrm{R}$ & $\begin{array}{l}\text { R } \\
\text { Squar } \\
\mathrm{e}\end{array}$ & $\begin{array}{l}\text { Adjuste } \\
\mathrm{d} \quad \mathrm{R} \\
\text { Square }\end{array}$ & $\begin{array}{l}\text { Std. of } \\
\text { The } \\
\text { Estimate } \\
.\end{array}$ \\
\hline 1 & $\begin{array}{l}.91 \\
6\end{array}$ & .839 & .836 & .33207 \\
\hline
\end{tabular}

Berdasarkan output tabel 4.10 dapat dilihat bahwa nilai $R$ square 0,839 dan diubah menjadi persen yaitu $83,9 \%$. Hal ini menunjukkan bahwa kemampuan Disiplin Kerja memiliki pengaruhnya terhadap kinerja karyawan di klinik tumbuh kembang Yamet adalah sebesar 83,9\% serta $16,1 \%$ yaitu pengaruh variabel variable bebas lainnya dimana tidak dilakukan penelitian disini.

\section{Hasil Analisis Regresi / $X_{2}$ terhadap} Y

Tabel 4. 11 Hasil -Analisis Regresi / X2 terhadap $Y$

\begin{tabular}{|ll|l|l|}
\hline \multirow{2}{*}{ Model } & \multicolumn{2}{|l|}{ Unstandardized Coefficients } \\
\cline { 2 - 3 } & $\mathrm{B}$ & Std. Error \\
\hline 1 & (Constant) & .152 & .233 \\
\multicolumn{2}{|l|}{ X2 } & .911 & .058 \\
\hline \multicolumn{2}{|c|}{ Berdasarkan output pada } \\
\hline
\end{tabular}
tabel 4.11 persamaan regresi dalam penelitian adalah: $\hat{\mathrm{Y}}=$ $0,152+0,911 \quad \mathrm{X}_{2}$ Penjelasannya adalah : Konstanta sebesar 0,152 menyatakan bahwa tanpa variabel disiplin kerja, kinerja yaitu 0,152 . Nilai coefficents sebesar 0,911. Artinya jika disiplin kerja naik sebesar satu satuan maka kinerja akan naik sebesar0,911. Pada persamaan tersebut dapat dilihat bahwa disiplin kerja memiliki kemampuan mempengaruhi 
kinerja karyawan. Hal ini menunjukkan bahwa kinerja karyawan dapat dipengaruhi oleh disiplin kerja.

\section{Hasil Pengujian Pengaruh}

Budaya Organisasi dan Disiplin

Kerja , terhadap Kinerja

Karyawan.

Tabel 4.12 .Hasil Uji F Pengaruh Bu-daya Or-ganisasi dan DisiplinKerja pada Kinerja Karyawan

\begin{tabular}{|l|l|l|l|l|l|l|}
\hline Model & & $\begin{array}{l}\text { Sum of } \\
\text { Square } \\
\text { s }\end{array}$ & $\begin{array}{l}\text { Mean } \\
\text { Squar } \\
\text { e }\end{array}$ & F & Sig. \\
\hline $\begin{array}{l}1 \\
\begin{array}{l}\text { Regre } \\
\text { ssion } \\
\text { Resid } \\
\text { ual } \\
\text { Total }\end{array}\end{array}$ & 30.544 & 2 & $\begin{array}{l}15.27 \\
2\end{array}$ & $\begin{array}{l}304.9 \\
67\end{array}$ & .00 \\
$0^{\mathrm{b}}$ \\
\hline
\end{tabular}

Berdasarkan output 4.12 dapat dilihat $\mathrm{F}$ hitung (304.967) lebih dari nilai $\mathrm{F}$ table $(2,79)$ dan sig. $\alpha(0,000)$ lebih - kecil daripada alpha 5\% $(0,05)$. Dengan hasil yang tertera didapat $\mathrm{H}_{\text {o ditolak }} \mathrm{H}_{\text {a }}$. diterim. secara simultan bu-daya Organisasi dan disiplin kerja memiliki pengaruh signifikan serta positif pada ki-nerja kar- di Klinik Tumbuh Kembang Yamet.

\section{Hasil Koefisien Determinasi (R-Square) $\mathrm{X}_{1}, \mathrm{X}_{2}$, terhadap Y.}

Tabel 4.13.Hasil Koefisien Determinasi (RSquare) X1, X2 terhadap Y

\begin{tabular}{|l|l|l|l|l|}
\hline Mode & & & $\begin{array}{l}\text { Std. } \\
\text { Rrror } \\
\text { Square }\end{array}$ & $\begin{array}{l}\text { Adjusted } \\
\text { R } \\
\text { Square }\end{array}$ \\
\hline 1 & $\begin{array}{l}.964 \\
\text { of } \\
\text { Estima } \\
\text { te }\end{array}$ \\
\hline
\end{tabular}

Berdasarkan output tabel 4.13 dapat dilihat bahwa nilai $\mathrm{R}$ Square 0,928 dan diubah menjadi persen yaitu $92,8 \%$. Artinya bahwa persentase budaya or-ganisasi serta disiplin kerja pada ki-nerja karyawan Klinik Tumbuh Kembang Yamet sebesar $92,8 \%$, sisanya 7,2 \% dipengaruhi variabel bebas lain yang tidak diteliti dalam penelitian ini.

Hasil Analisis Regresi / $\mathrm{X}_{1}, \mathrm{X}_{2}$ terhadap $\mathrm{Y}$

Tabel 4. 14. -Hasil - Analisis Regresi X1, X2 terhadap Y.

Berdasarkan pada output tabel -4.14, didapat : $\hat{Y}=0.249+$ $0,638 \mathrm{X}_{1}+0,406 \mathrm{X}_{2}$. Angka konstanta 0.249 yaitu tidak ada pengaruhnya dari variabel- variabel $X_{1}, X_{2}$,

\begin{tabular}{|ll|l|l|}
\hline \multirow{2}{*}{ Model } & \multicolumn{2}{|l|}{$\begin{array}{l}\text { Unstandardized } \\
\text { Coefficients }\end{array}$} \\
\cline { 2 - 3 } & $\mathrm{B}$ & Std. Error \\
\hline 1 & (Constant & .249 & .165 \\
& X1 & .638 & .083 \\
X1 & .406 & .076 \\
& & \\
\hline & & \\
\end{tabular}

dengan cara secara simultan, Y memiliki value 0.249 serta koefisien 0,638 memberikan pengertian sdengan bertambahnya 1 satuan pada va-riabel $\mathrm{X}_{1}$ menembeh tingkat kinerja 0,638 dengan $\mathrm{X}_{2}$ tidak berubah, 0,406 memberi arti dengan bertambahnya 1 satuan pada variabel $\mathrm{X} 2$ menambah tingkat kinerja 0,406, dengan $\mathrm{X}_{1}$ tidak berubah. Disimpulkan Budaya organisasi serta Disiplin Kerja punya pengaruh atas kinerja karyawan klinik tumbuh kembang Yamet. Hal ini menunjukkan bahwa kinerja karyawan klinik 
tumbuh kembang Yamet dapat dipengaruhi oleh bu-daya or-ganisasi serta disiplin kerja.

\section{PEMBAHASAN}

Maka dapat dilakukan pembahasan berdasar frekuensi pemilihan opsional pada setiap pernyataan variabel independen dan dependen (variabel budaya organisasi,variabel disiplin kerja , variabel Kinerja karyawan) yang diajukan kepada responden penelitian sebagai berikut:

\section{Variabel Budaya Organisasi} $\left(\mathbf{X}_{1}\right)$

Didasarkan kuesioner des-kriptif analitik dari sumber primer pada va-riabel bu-daya Or-ganisasi, maka diketahui tanggapan terhadap budaya organisasi yang ada di klinik tumbuh kembang Yamet menyatakan setuju yaitu sebanyak 38,6 \% atau sebanyak 19 orang. Namun yang menyatakan ragu- ragu sebanyak $28,6 \%$ atau sebanyak 14 orang. Artinya budaya organisasi dirasa sudah cukup baik, namun harus terus dipertahankan agar secara konsisten untuk kedepannya dapat menjadi suatu norma yang mengarahkan prilaku bagi organisasi, dan diharapkan lebih terbuka terhadap lingkungan internal, eksternal dan lingkup profesionalisme, mempunyai kepercayaan pada rekan kerja, sehingga dapat dijadikan salah satu dasar pengambilan keputusan, Menurut Boejong Lukito (1995) Budaya Organisasi yang kuat akan berpengaruh positif pada kinerja bisnis.

\section{Variabel Disiplin kerja $\left(\mathbf{X}_{2}\right)$}

Berdasarkan hasil deskriptif analitik jawaban responden variabel disiplin kerja , maka diketahui tanggapan responden terhadap disipilin kerja di Klinik tumbuh kembang Yamet yang menyatakan setuju sebanyak $34 \%$ atau sebanyak 17 orang. Adapun yang menyatakan ragu-ragu sebanyak $42 \%$ atau sebanyak 17 orang. Artinya disiplin kerja yang dirasa karyawan cukup baik, namun harus terus ditingkatkan agar memotivasi karyawan menumbuhkan semangat dalam bekerja sehingga kinerja yang dihasilkanpun optimal sesuai target.

Menurut Malthis \& Jackson ( 2004 ) bahwa disiplin kerja berkaitan dengan perilaku karyawan dan berpengaruh terhadap kinerja. Makin tinggi disiplin kerja seseorang maka makin tinggi pula hasil kinerja karyawan .

\section{Variabel Kinerja Karyawan (Y)}

Didasarkan dari kuesioner deskriptif analitik data primer pada ki-karyawan, maka diketahui tanggapan responden terhadap ki-nerja -karyadi Klinik Yamet yang menyatakan setuju sebanyak 33\% atau sebanyak 17 orang. Adapun yang menyatakan ragu-ragu sebanyak 29,3\% atau sebanyak 15 orang. Artinya kinerja yang dirasa cukup baik, namun kinerja tersebut harus terus ditingkatkan sehingga visi misi Klinik tumbuh kembang Yamet dapat tercapai optimal.

\section{KESIMPULAN DAN SARAN.}

\section{A. Kesimpulan.}

1.Budaya organisasi berpengaruh positif dan signifikan terhadap kinerja karyawan. Pengaruh 
variabel budaya organisasi terhadap variabel kinerja pada Klinik Tumbuh Kembang Yamet adalah sebesar $88,6 \%$ sisanya sebesar $\quad 11,4 \% \quad$ merupakan pengaruh dari variabel bebas lainnya yang tidak diteliti. Persamaan regresi linier $\hat{Y}=0.75+$ $1.020 \mathrm{X}_{1}$.

2.Di-siplin ke-pengaruhnya signifikan serta positip pada kinerja karyawan. Pengaruh varibel disiplin kerja terhadap variabel kinerja pada Klinik Tumbuh Kembang Yamet adalah sebesar $83.9 \%$. Sisanya sebesar $16.1 \%$ merupakan pengaruh dari variabel bebas lainnya yang tidak diteliti dalam penelitian . Persamaan regresi linier $\hat{Y}=0.152+0.911 \mathrm{X}_{2}$.

3. Budaya organisasi dan disiplin kerja secara simultan berpengaruh positif dan signifikan terhadap kinerja karyawan. Budaya organisasi dan di-siplin kerj-a dalam bersamaann menjelaskan pengaruhnya pada variabel kiner-ja k-aryawan di Klinik tumbuh kembang Yamet adalah sebesar $92,8 \%$, sisanya sebesar $7,2 \%$ merupakan pengaruh dari variabel bebas lainnya yang tidak diteliti disini.

Persamaan regesi linier $\hat{Y}=0,249+$ $0,638 X_{1}+0,406 X_{2}$.

\section{B. Saran}

Bagi Klinik tumbuh kembang Yamet Berdasar pada hasil quesioner ketiga variabel didapatkan temuan sebagai berikut:

1. Budaya

Organisasi

14 responden $(28,6 \%)$ menyatakan ragu- ragu pada sub indikator percaya pada rekan kerja, oleh karena itu disarankan kepada pimpinan klinik tumbuh kembang Yamet harus membudayakan lagi sikap lebih terbuka, lebih peka terhadap lingkungan internal eksternal, mampu berkomunikasi efektif dalam organisasi ybs, mampu membangun teamwork yang solid.

2. Disiplin Kerja 14 orang responden (28\%) menyatakan ragu-ragu pada sub indikator sanksi hukuman, maka untuk menyelesaikan perihal ini pihak Klinik Yamet harus lebih memperhatikan lagi aspek sanksi hukuman yakni dengan memberikan teguran kepada karyawan /karyawati yang lalai atau melanggar aturan. Dengan disiplin kerja yang tinggi maka makin tinggi dan optimal pula kinerja karyawan, serta menumbuhkan semangat kerja yang tinggi dalam melaksanakan tugasnya

3. Kinerja Karyawan 29,3 responden (15\%) menyatakan ragu - ragu pada sub indikator target dan waktu penyelesaian laporan akhir kegiatan, di sarankan Klinik Tumbuh Kembang Yamet harus lebih meningkatkan monitoring terhadap kedisiplinan kinerja dan memperhatikan alokasi tugas karyawan / karyawati (jobdesk).

\section{DAFTAR PUSTAKA}

Djarwanto \& Subagyo,2012,Statistik Induktif, BPFE, Yogyakarta

Edi $\begin{array}{r}\text { Sutrisno,2011,Manajemen } \\ \text { Sumber Daya Manusia, Kencana, } \\ \text { Jakarta }\end{array}$


Hasibuan, Malayu., 2008, Manajemen Sumber Daya Manusia, Bumi aksara, Jakarta.

Hasibuan, Malayu., 2011, Manajemen: Dasar, Pengertian dan Masalah, Bumi Aksara: Jakarta

Fuad Masud,2004, Survei Diagnosis Organisasional ( konsep \& Aplikasi), Undip

Gozali,2006,Aplikasi Analisis Multivariate dengan Program SPSS, edisi 4,Undip,Semarang

Siagian, Sondang, 2013, Perilaku Organisasi, Salemba Empat, Jakarta

Sugiyono, 2013, Statistika untuk Penelitian, Edisi VI, Alfabeta, Bandung.

(2012) Metode Penelitian Kuantitatif, Kualitatif , Alfabeta, Bandung

(2011) Metode Penelitian Kuantitatif, Kualitatif dan $R \& D$ cetakan ke sebelas,,Alfabeta, Bandung.

(2006) Aplikasi Analisis Multivariat deangan program SPSS, cetakan 4; Semarang

Suharto dan Cahyo, 2006, Pengaruh Budaya Organisasi Sondong.Vol 15. Erlangga. Jakarta.

Suharto \& Cahyono, Budi. 2011, , Kepemimpinan dan Motivasi Terhadap Kinerja Sumber Daya Manusiadi Sekretariat DPRD provinsi Jawa Tengah, Jurnal
Riset Bisnis Indonesia Vol. 1 No.1: p.13-30.

Sumarsono, Sonny, 2013, Metode Riset Sumber Daya Manusia, STIE YKPN Yogyakarta.

Suranta, 2006, Manajemen Sumber Daya Manusia Vol 2. JRBI, Yogyakarta.

Veithzal Rivai, 2011,Manajemen Sumber Daya Manusia untuk Perusahaan, Raja grafindo Persada, Jakarta

Waridin dan Bambang Guritno, 2009, Manajemen Pemerintahan, Pustaka Utama, Jakarta .

Wirawan, 2007, Budaya dan iklim organisasi, Salemba Empat, Jakarta

Wibowo,2011,ManajemenKinerja, $\mathrm{R}$ ajawaliPers; Jakarta. 